\title{
The role of biologics in eosinophilic esophagitis
}

\author{
O papel dos imunobiológicos na esofagite eosinofílica
}

\author{
Inara Patrícia Desidério", Igor Garcia Sanches de-Souza', Guilherme Gonçalves Ferrigolli ${ }^{1}$, \\ Marcelo Vivolo Aun ${ }^{2}$, Renata Rodrigues $\mathrm{Cocco}^{2}$
}

\section{ABSTRACT}

Eosinophilic esophagitis (EoE) is a chronic inflammation in the esophageal mucosa driven by an antigen-mediated abnormal immune response with apparent increasing prevalence worldwide. Genetically predisposed individuals present with a dysfunctional esophageal barrier and an abnormal immune response mediated by Th2 and IgE against certain allergens. Consequently, esophageal lesions can cause dysmotility, fibrosis and loss of esophageal barrier function. Clinical manifestations are age-related and include symptoms of esophageal dysfunction. Diagnosis is established by specific histological features associated with the presence of at least 15 eosinophils per high-power field. Management of EoE includes control of allergic diseases with diet restrictions and/or pharmacological treatment with proton-pump inhibitors and corticosteroids, not completely effective and limited by possible side effects and impairment of quality of life. Although immunological mechanisms of EoE are still less clear than other allergic diseases, biologic trials indicate some promising perspectives for EoE management. The purpose of this review is to present the current evidence of biologic drugs as options for EoE treatment.

Keywords: Biological products, diagnosis, endoscopy.

\section{Introduction}

Eosinophilic esophagitis (EoE) is a chronic inflammation in the esophageal mucosa driven by an antigen-mediated abnormal immune response, expressed by clinical manifestations from esophageal dysfunction and histologic findings of

\section{RESUMO}

Esofagite eosinofílica (EOE) é uma inflamação crônica da mucosa esofágica com resposta imune antígeno-mediada anormal e com aparente aumento mundial na prevalência. Indivíduos geneticamente predispostos se apresentam com quadro de disfunção da barreira esofágica e uma resposta imune, mediada por TH2 e IGE, anormal contra certos alérgenos. Consequentemente, lesões esofágicas podem causar dismotilidade, fibrose e perda da função de barreira. O quadro clínico apresenta variação conforme idade e inclui sintomas de disfunção esofágica. O diagnóstico é estabelecido por achados histológicos específicos associados à presença de, ao menos, 15 eosinófilos por campo de alta potência. O manejo inclui controle do quadro alérgico com restrição dietética e/ou tratamento medicamentoso com bloqueadores da bomba de prótons e corticosteroides. São tratamentos sem completa efetividade, com efeitos colaterais e prejuízo na qualidade de vida. Ainda que os mecanismos imunológicos da EOE sejam menos claros que as demais doenças alérgicas, novos ensaios com imunobiológicos salientam uma perspectiva promissora de tratamento para a EOE. O objetivo desta revisão é apresentar as atuais evidências de uso de imunobiológicos como uma nova opção de terapêutica para a esofagite eosinofílica.

Descritores: Produtos biológicos, diagnóstico, endoscopia.

at least 15 eosinophils per high-power field on light microscopy. ${ }^{1}$

Its prevalence seems to be increasing worldwide and recent data estimates to be between 10 and 57 cases/100,000 persons. ${ }^{2}$ Likewise, the incidence

1. Faculdade Israelita de Ciências da Saúde Albert Einstein - São Paulo, SP, Brazil.

2. Hospital Israelita Albert Einstein - São Paulo, SP, Brazil. 
presents with the same trend, presumably because of better clinical recognition and, therefore, an enlarged number of diagnosis. ${ }^{2}$ Male individuals are more frequently affected and such preference suggests that an X-linked gene could be associated. ${ }^{3}$ It is more common in children and adolescents and is frequently associated with a personal or familial history of allergic disorders, mostly represented by atopic diseases. ${ }^{3}$

Clinical manifestations of EoE are age-related and include a range of dyspeptic, allergic and respiratory symptoms. ${ }^{1}$ The disease has a strong relationship with atopic diseases, such as allergic rhinitis, asthma and atopic dermatitis and is usually triggered by foods, where cow's milk represents the most common culprit food. There seems to be a relation between EoE and gastroesophageal reflux disease (GERD), although its association is complex and not well understood yet.${ }^{4}$ As a consequence of the nonspecific symptoms, diagnosis of EoE can be delayed, which can substantially worsen prognosis. ${ }^{5}$

Current management includes food restriction, proton-pump inhibitors (PPIs) and swallowed corticosteroids. Although partially effective, a considerable proportion of steroid-refractory patients can still be observed; adherence rates to daily medication, particularly in the long term, are low and response to steroids might be lost over time. ${ }^{5}$ In parallel, and especially in childhood, restriction diets imply several issues, including quality of life and nutritional problems. Therefore, there is an urgent need for better management options, where biologics tend to be a promising expectation. ${ }^{6}$

\section{Pathophysiology}

The underlying mechanisms involved in the pathophysiology of EoE are vast and complex, with diverse implicated pathways, immune cells and cytokines. Although not totally elucidated yet, the basis of the disease relies on an antigen-mediated immune response capable of recruiting eosinophils into the esophagus and the consequences of a cascade of released inflammatory mediators. ${ }^{7}$

Genetically predisposed individuals present with a dysfunction in epithelial esophageal barrier caused by reduced expression of desmoglein 1 and genetic variants in the filaggrin gene, which enable the passage of antigens. Pursuant to, epithelial and resident cells are stimulated by food and environmental allergens to release thymic stromal lymphoprotein
(TSLP) and interleukin (IL-) 33. ${ }^{8}$ The proinflammatory mediators, named alarmins, activate leukocytes such as basophils, mast cells and lymphoid innate cells to secrete T helper (Th) 2 cytokines, especially IL-4, IL-5 and IL-13. In response to contact of allergens by antigen presenting cells (APCs), Th2 cytokines induce naive T-CD4 (Th0) cells into Th2 effector cells, which amplifies the type-2 inflammation profile cytokines. Furthermore, IL-5, eotaxin and RANTES recruit eosinophils into the esophageal mucosa. Eosinophils secrete mediators such as eosinophilic peroxidase, eosinophilic cationic protein and major binding protein, which directly cause tissue damage and esophageal dysmotility. ${ }^{9}$

Secondary effects of Th2 cytokines, mainly IL-4 and IL-13, include impairment of barrier function and tissue remodeling. IL-4 stimulates IgE production. Thus, an elevated number of mast cells and their degranulation in esophageal epithelium suggest that EoE is associated with type 1 hypersensitivity. Simultaneously, IL-13 seems to have a central role in EoE pathogenesis, independently of $\mathrm{IgE}$ and mast cells. It has been shown that IL-13 is partially responsible for esophageal eosinophilia. In addition, overexpression of IL-13 can lead to prominent esophageal remodeling with epithelial hyperplasia, angiogenesis and collagen deposition, in an eosinophilic-independent pathway. ${ }^{10}$

In parallel, IL-5 generates a substantial activation, proliferation, survival and chemotaxis of eosinophils to the tissue, responsible for collagen deposition, remodeling and additional tissue damage. Consequently, patients reveal esophageal lesions, extracellular matrix damages, fibrosis, dysmotility and loss of esophageal barrier function.

Although IL-4, IL-5 and IL-13 are considered major Th2 cytokines in the pathogenesis of EoE, several other cytokines play substantial roles in the inflammatory process. IL-9 seems to have an important function on epithelial barrier disruption and mast cell recruitment. ${ }^{11}$ It has been reported that IL-15 is overexpressed in animal models of EoE. ${ }^{12}$ Furthermore IL-33 increased expression is associated with EoE in childhood. ${ }^{8}$ Besides them, an increasing number of different small molecules are a current focus of research and are possible targets for management interventions. ${ }^{6}$

Recent studies have demonstrated the potential role of IgG4 in EoE, which seems to have an increased production and can present with elevated seric and esophageal mucosal levels. Although further 
studies are needed for elucidation of its role in EoE phisiopatology, dietary and pharmacological treatment appear to reduce IgG4 levels. ${ }^{13}$ The major biological functions of IgE, IL-4, IL-13 and IL-5 in genesis of EoE are summarized in Table 1.

\section{Genetics}

EoE has a genetic background. It was described that there is a $41 \%$ risk in homozygous twins and $22 \%$ in dizygotic twins, whereas prevalence is about $0.05 \%$ in the general population. The EoE "transcriptome" comprises 574 genes expressed in healthy and affected children and the various roles illustrate the complexity of EoE pathophysiology. ${ }^{9}$

Genetic studies of EoE have been trying to explain the complex relationship between GERD and EoE on account of GERD being able to cause alterations of the epithelial barrier and possibly lead to EoE and the response to PPIs in both diseases. Nevertheless, no particular gene has been found to explain the impact of GERD in EoE. ${ }^{9}$

Knowledgement of genetic variants in EoE transcriptome provides a deep understanding of the mechanisms of EoE, but there are still many genes remaining with an unknown role in pathophysiology. Some of them which were already described might have impact in EoE pathogenesis, such as overexpression of CCL26 (eotaxin-3), which is induced by IL-13, and underexpression of filaggrin, which leads to the loss of epidermal cell differentiation and impaired barrier function. ${ }^{9}$ The overexpression of malfunctional genes, such as CAPN14, leading to architectural changes, more antigens traffic, and variations in the microbial imbalance in esophagus can enhance imparied barrier function in patients with EoE and contribute to the esophageal inflammation. ${ }^{9}$

Further studies for identification of novel rare genetic variants of EoE will provide insights into the complex pathophysiology of EoE and associated diseases.

\section{Clinical manifestations}

The consequences of the wide inflammation previously described points to clinical manifestations of chronic and age-related symptoms of esophageal dysfunction, may expressed as dysphagia, inappetence, heartburn, regurgitations, vomiting, chest pain, odynophagia, abdominal pain and/or failure to thrive. ${ }^{1}$

Eosinophilic esophagitis is associated with atopy and other allergic conditions and patients frequently have multiple food allergies (cow's milk, egg, wheat, soy), with atopic symptoms or suggestive family history of atopic disorders. ${ }^{1,4}$

The broad spectrum of symptoms and associated atopic conditions directly implicate an impaired quality of life. Delayed diagnosis and difficulty in clinical management also have a major impact on the patient's life.

\section{Table 1}

Role of IgE and main Th2 cytokines (IL-4, IL-13 and IL-5) in eosinophilic esophagitis (EoE) pathogenesis

\section{Molecule Role of eosinophilic esophagitis pathogenesis}

IgE Eosinophilic activation; esophageal dysmotility and remodeling; IgE mediated reactions (food allergies, atopic diseases)

IL-4 Impairment of barrier function and tissue remodeling; stimulation of IgE release

IL-13 Esophageal eosinophilia $\rightarrow$ esophageal remodeling

IL-5 Recruitment of eosinophils into the esophageal mucosa; eosinophil activation and proliferation $\rightarrow$ esophageal remodeling and collagen deposition 
Due to the nonspecific symptoms of EoE, the disease usually progresses for as long as four years before diagnosis is confirmed. ${ }^{5}$ Figure 1 summarizes the different clinical features of EoE according to age.

\section{Diagnosis}

Based on the symptoms a patient is presenting, clinical suspicion for EoE can be established and a detailed investigation can be started.

The gold standard for diagnosis of EoE is the upper gastrointestinal endoscopy (esophagogastroduodenoscopy - EGD) with esophageal biopsies from proximal, medial and distal sites. ${ }^{4}$ Diagnostic criteria include the presence of at least 15 eosinophils per high-power field and specific endoscopic features, such as eosinophilic microabscesses, mucosal edema, exudate, longitudinal furrows, circular esophageal rings and esophageal stenosis. ${ }^{4}$ Diagnosis can only be confirmed in the presence of signs and symptoms compatible with esophageal dysfunction associated with endoscopic and histological findings.

Besides the endoscopic findings and clinical manifestations, it is crucial to discard differential diagnosis such as GERD, achalasia, hypereosinophilic syndrome, Crohn's disease, viral and fungal infections, connective tissue disorders, hypermobility syndromes and autoimmune disorders.

Although EoE is associated with atopic diseases, mostly food allergies, specific lgE blood tests and skin prick tests show poor sensitivity and specificity. It's important to evaluate the most prevalent allergies in EoE patients to help with management and prevent anaphylaxis and in that scenario the $\operatorname{IgE}$ and skin tests can be useful. ${ }^{4}$ Therefore, because of the lack of predictive positive value (44\%), ${ }^{14}$ these tests alone are not sufficient for EoE diagnosis. ${ }^{4,14,15}$

A suggestive algorithm for EoE diagnosis is shown in Figure 2.

\section{Management of EoE}

\section{Diet}

Dietetic management of individuals with EoE has shown to be an adequate treatment with good clinical and histological remission rates, especially in pediatric patients. Three alternatives are most used: elementary diet, allergy testing-directed elimination diet and empiric elimination diet. Although superior in efficacy, use of a strict amino acid formula has several limits, including taste, limited meal variety and cost. ${ }^{14}$



Figure 1

Clinical manifestations of eosinophilic esophagitis according to age 


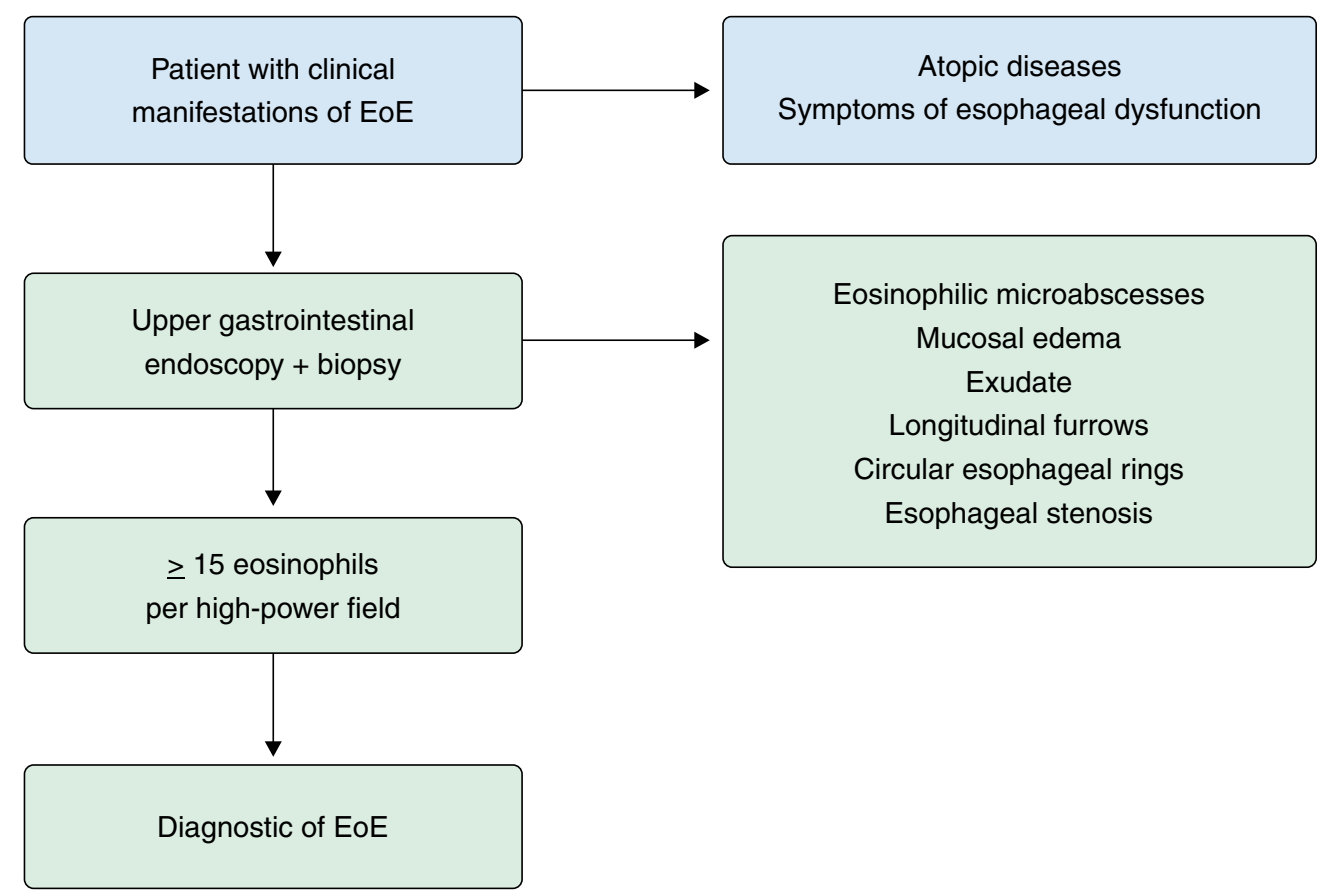

Figure 2

Suggestive algorithm for eosinophilic esophagitis diagnosis (modified from Dellon ES, et al. ${ }^{20}$ )

Since $\lg E$ is not necessarily required for triggering EoE, restricted diets based on specific IgE tests present limited success. ${ }^{15}$ Atopy patch testing had been analyzed for the same purposes but the lack of evidence of accuracy or validation restrain its application as restriction guidance, even if combined with skin prick tests. ${ }^{16}$

Empiric elimination diet consists in the elimination of the most common prevalent culprit foods in the pathogenesis of EoE and comprises six (cow's milk, egg, soy, wheat, peanuts/tree nuts, and fish/ shellfish), four (milk, wheat, egg, and soy), two (milk and wheat) or only milk. ${ }^{17,18}$ After a period of 6-8 weeks, foods should be reintroduced, if possible after repeated endoscopies, which is a considerable problem in pediatric patients. Although better accepted over elemental diet and more effective than allergy testing-directed elimination diet, deprivation of several nutrients and emotional stigma make a difficult practice when maintained for prolonged time.

\section{Corticosteroids}

Both swallowed fluticasone or budesonide demonstrate efficacy in clinical and histopathology of patients with EoE. ${ }^{19}$ Although long-term use is currently indicated for maintenance therapy, treatment is not free of side effects, especially oral and esophageal candidiasis. ${ }^{20}$

\section{Proton-pump inhibitors (PPI)}

A PPI should be considered as a potential early or initial treatment or if diet or steroid therapy is used as a first line therapy but is ineffective on follow-up endoscopy. ${ }^{20}$ Differently of previous beliefs, PPIresponsive patients must be reclassified as having EoE.

\section{Surgical treatment}

Esophageal dilation is an alternative therapy for patients with remodeling processes caused by 
EoE. It is especially useful in the adult population to treat associated symptoms. It has not shown any histological response and is exclusively used in severe esophageal stenosis or persistent dysphagia.

Figure 3 shows an algorithm proposed for management of EoE.

\section{Biologics}

Due to all the facts presented previously regarding worries about increasing prevalence of EoE, its clinical manifestations and limitations and/or incomplete effectiveness of current treatment options, there is an urgent need to deepen safer and more efficient tools for management of the disease.

Recently, advances in the monoclonal antibodies (mAbs) or biologics field have been allowing different therapeutic approaches for several immunological diseases. It would be reasonable to evaluate, therefore, whether biologic drugs scientifically approved for treatment of allergic diseases (e.g. asthma, atopic dermatitis, chronic rhinosinusitis) ${ }^{21,22}$ could have some role in EoE management.

\section{Anti IgE (Omalizumab)}

Omalizumab is a humanized $\mathrm{mAb}$ that targets circulating IgE and which has been efficaciously used to treat allergic asthma and chronic spontaneous urticaria. ${ }^{23,24}$ There are few case reports of successful treatment of EoE with omalizumab. ${ }^{25,26}$ To date, only two clinical trials have been published and both demonstrated poor histological improvement and clinical remission with this drug, suggesting eosinophilic inflammation is not IgE-mediated. ${ }^{27,28} \mathrm{~A}$ unique double blind placebo controlled (DBPC) phase 2 study including 30 adult and teenager patients(12-60) was already published and showed no histological or clinical recovery by using omalizumab. ${ }^{28}$

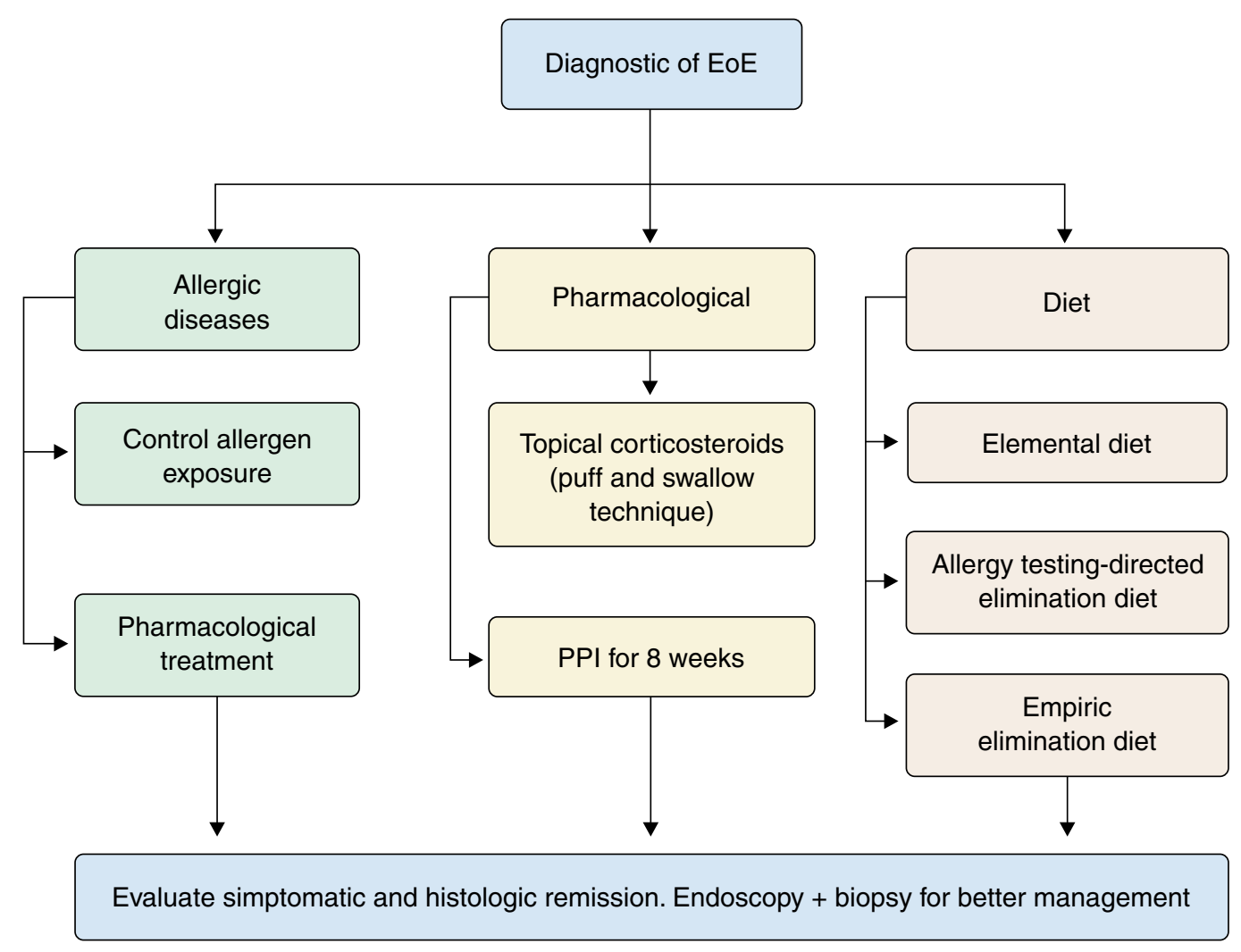

Figure 3

Algorithm for management of eosinophilic esophagitis (EoE) 


\section{Anti IL-5 (Reslizumab, Mepolizumab and Benralizumab)}

Reslizumab, Mepolizumab and Benralizumab are mAbs that antagonize the IL-5 pathway. While Benralizumab blocks the IL-5 receptor that is expressed in the membrane of basophils and eosinophils and induces their death, reslizumab and mepolizumab bind to the IL-5 molecule directly, preventing activation of the IL-5 receptor. ${ }^{29-31}$

In a DBPC study, 226 children received Reslizumab infusion versus placebo and the results showed improvement in histological features with a $67 \%$ reduction in eosinophil counts when compared to a $24 \%$ reduction within the control group $(p<0.001) .{ }^{32}$ However, no benefits in clinical symptoms were described. ${ }^{32}$ In parallel, a retrospective 9 year study analyzed 12 patients who received reslizumab treatment for EoE and showed better control of clinical manifestations. ${ }^{31}$ It is considered a well tolerated medication and the most common adverse effects described in large asthma clinical trials were cough and congestion. 30

A DBPC clinical trial was conducted with 84 children with EoE using mepolizumab in different doses. There was improvement in both clinical symptoms and histological eosinophilia. However, clinical remission was only achieved in $8.8 \%$ of the kids. ${ }^{33}$ There was a clinical trial including 11 adults with $\mathrm{EoE}^{34}$ and although there was a decrease in mucosal eosinophilic inflammation, mepolizumab did not induce clinical benefits compared to placebo. Moreover, authors evaluated duodenal inflammation of those 11 individuals and could not find differences in eosinophilic or lymphocytic inflammation in duodenal mucosa. ${ }^{35}$

Despite its mechanism of action suggesting a possible role of benralizumab in EoE management, there are no case reports published with this drug to treat EoE. There is a promising phase three clinical trial in progress with 170 patients, but as it was initiated in September 2020, results are still not available. ${ }^{36}$

\section{Anti IL-4 and IL-13 (Dupilumab)}

Dupilumab is a fully human IgG4 mAb that targets the IL-4 receptor alpha subunit that is endogenously bound by both IL-4 and IL-13. It was approved by the FDA and Brazilian regulatory agency (ANVISA) for the treatment of moderate to severe atopic dermatitis, severe eosinophilic asthma and chronic rhinosinusitis with nasal polyps. ${ }^{37}$ This drug inhibits the effects of cytokines that are main factors in the Th2 response and has been studied for allergic diseases treatment for the last few years, with promising results.

Whereas EoE has an important allergic component that implies the Th2 immune response in its pathophysiology, dupilumab is considered a possible therapy for the disease. The only published study is a phase 2 randomized, double-blind, placebo-controlled clinical trial that evaluated adults with EoE and the results showed that dupilumab reduced dysphagia, histologic and endoscopic features compared to placebo. 40 There are phase 3 trials in progress trying to support the efficacy and safety of dupilumab for EoE treatment in pediatric and adult patients separately. ${ }^{38,39}$

Although more evidence is needed to establish efficacy and safety for EoE treatment with dupilumab, especially in children, promising results are emerging and could widen modalities and quality of EoE treatment.

\section{Others: small molecules, IL-33, TNF alpha}

Other biologics are being evaluated as addon therapy for EoE. Studies with those biologics registered in clinicaltrials.gov or already published are summarized in Table 2.

IL-33 is an important citocine in the activation of type $2 \mathrm{~T}$ helper cells. Although its circulating level is not high in pediatric patients with EoE, it appears to have an important role in reducing antigenic tolerance and, therefore, favoring EoE occurrence in the pediatric population. ${ }^{41}$ TNF- $\alpha$ imunoglobulin (infliximab) was tested in 3 adult patients with severe EoE in order to see if there could be any benefit in treatment. Although none of them had any important adverse events, the treatment failed to reduce activity of disease and laboratorial/endoscopic improvement. ${ }^{46}$

\section{Future perspective}

For the future, there is a tendency to increase studies on the efficiency of the immunobiologicals, given that there are ongoing clinical trials and published articles that foster hope for the use of this class of medication.

Considering Omalizumab, the clinical results are not so promising since they did not show histological or clinical improvement, so there may be a tendency for this drug to be left aside when it comes to the treatment of EoE. 
Table 2

Most promising biologicals for eosinophilic esophagitis (EoE) treatment

\begin{tabular}{lccc}
\hline Biologic & Mechanism of action & Study phase & References \\
\hline Mepolizumab & Anti IL-5 & 2 & $33-35$ \\
Reslizumab & Anti IL-5 & 2 and 3 & 30,32 \\
Lirentelimab & Anti Siglec-8 & 2 and 3 & 42 \\
QAX576 & Anti IL-3 & 2 & 43 \\
Dupilumab & Anti IL-4 e IL-13 & 2 and 3 & $38-40$ \\
Omalizumab & Anti IgE & 1 and 2 & 27,28 \\
RPC4046 & Anti IL-13 & 2 & 44,45 \\
Infliximab & Anti TNF- $\alpha$ & 2 & 46 \\
\hline
\end{tabular}

In view of Reslizumab, there are better prospects for the future as published studies have shown a reduction in eosinophil counts and a reduction in symptoms. However, one of the studies had only 12 patients, which suggests a need for further studies to better investigate the effect of this drug.

Mepolizumab shows similar results in different studies, but it's not an elucidate result since there is clinical improvement in one study and not in another, and is also a source for new studies.

Regarding Dupilumab, we also have a good perspective for the future, as studies have shown a reduction in symptoms and histological improvement of patients receiving treatment, however more studies should be carried out to establish a safe pharmacological profile.

Thus, there is a good prospect for the future with immunobiologicals that should count on more studies to better establish the pharmacological profile and treatment efficacy. The development of studies can occur both in the drugs that already exist and in the emergence of new drugs with similar immunobiological mechanisms. ${ }^{47}$

The prospects of a safe and effective treatment for EoE with immunobiologicals in the future could be the key to better management and clinical control of this disease, significantly improving the quality of life of these patients.

\section{Conclusion}

Eosinophilic esophagitis represents a challenge for clinicians due to its increasing prevalence, broad spectrum of clinical manifestations, gaps in pathophysiology mechanisms and limitations of current treatment possibilities. Consequently, there is a pressing need to expand the therapeutic options and improve the quality of life. In that perspective, the emerging biological drugs could enable better management of the disease and create an innovative approach.

Despite progressive efforts for achieving the perfect drug, further studies are needed in order to establish their role as main treatment and/or adjuvant and possible benefits of association for better results.

\section{References}

1. Furuta GT, Katzka DA. Eosinophilic Esophagitis. N Engl J Med. 2015;373(17):1640-8.

2. Moawad FJ. Eosinophilic Esophagitis: Incidence and Prevalence. Gastrointest Endosc Clin N Am. 2018;28(1):15-25.

3. Atkins D, Furuta GT, Liacouras CA, Spergel JM. Eosinophilic esophagitis phenotypes: Ready for prime time? Pediatr Allergy Immunol. 2017;28(4):312-9.

4. Vinit C, Dieme A, Courbage S, Dehaine C, Dufeu CM, Jacquemot $S$, et al. Eosinophilic esophagitis: Pathophysiology, diagnosis, and management. Arch Pediatr. 2019;26(3):182-90. 
5. Shaheen NJ, Mukkada V, Eichinger CS, Schofield H, Todorova L, Falk GW. Natural history of eosinophilic esophagitis: a systematic review of epidemiology and disease course. Dis Esophagus. 2018;31(8):doy015.

6. Greuter T, Hirano I, Dellon ES. Emerging therapies for eosinophilic esophagitis. J Allergy Clin Immunol. 2020;145(1):38-45.

7. O'Shea KM, Aceves SS, Dellon ES, Gupta SK, SpergelJM, Furuta GT, et al. Pathophysiology of Eosinophilic Esophagitis.Gastroenterology. 2018;154(2):333-45.

8. Travers J, Rochman M, Miracle CE, Cohen JP, Rothenberg ME. Linking impaired skin barrier function to esophageal allergic inflammation via IL-33. J Allergy Clin Immunol. 2016;138:1381-3.

9. Ryu S, Lee KH, Tizaoui K, Terrazzino S, Cargnin S, Effenberger M, et al. Pathogenesis of Eosinophilic Esophagitis: A Comprehensive Review of the Genetic and Molecular Aspects. Int J Mol Sci. 2020;21(19):7253.

10. Zuo L, Fulkerson PC, Finkelman FD, Mingler M, Fischetti CA, Blanchard C, et al. IL-13 induces esophageal remodeling and gene expression by an eosinophil-independent, IL-13R alpha 2-inhibited pathway. J Immunol. 2010;185(1):660-9.

11. Forbes EE, Groschwitz K, Abonia JP, Brandt EB, Cohen E, Blanchard C, et al. IL- 9 and mast cell-mediated intestinal permeability predisposes to oral antigen hypersensitivity. J Exp Med 2008;205:897-913.

12. Zhu X, Wang M, Mavi P, Rayapudi M, Pandey AK, Kaul A, et al. Interleukin-15 expression is increased in human eosinophilic esophagitis and mediates pathogenesis in mice. Gastroenterology 2010;139:182-93.e7.

13. Lim AH, Wong S, Nguyen NQ. Eosinophilic Esophagitis and IgG4: Is There a Relationship? Dig Dis Sci. 2021 Feb 3. doi: 10.1007/ s10620-020-06788-0. Epub ahead of print. PMID: 33534011

14. Gonsalves NP, Aceves SS. Diagnosis and treatment of eosinophilic esophagitis. J Allergy Clin Immunol. 2020;145(1):1-7.

15. Ballmer-Weber BK. Value of allergy tests for the diagnosis of food allergy. Dig Dis. 2014;32(1-2):84-8.

16. Eckmann JD, Ravi K, Katzka DA, Davis DR, See JA, Geno DR, et al. Efficacy of Atopy Patch Testing in Directed Dietary Therapy of Eosinophilic Esophagitis: A Pilot Study. Dig Dis Sci. 2018;63(3):694--702.

17. Lucendo AJ, Arias A, Gonzalez-Cervera J, Yague-Compadre JL, Guagnozzi D, Angueira T, et al. Empiric 6-food elimination diet induced and maintained prolonged remission in patients with adult eosinophilic esophagitis: a prospective study on the food cause of the disease. J Allergy Clin Immunol. 2013;131:797-804.

18. Molina-Infante J, Arias A, Barrio J, Rodriguez-Sanchez J, SanchezCazalilla M, Lucendo AJ. Four-food group elimination diet for adult eosinophilic esophagitis: a prospective multicenter study. J Allergy Clin Immunol. 2014;134:1093-9.

19. Murali AR, Gupta A, Attar BM, Ravi V, Koduru P. Topical steroids in eosinophilic esophagitis: Systematic review and meta-analysis of placebo-controlled randomized clinical trials. J Gastroenterol Hepatol. 2016;31:1111-9.

20. Dellon ES, Liacouras CA, Molina-Infante J, Furuta GT, Spergel JM, Zevit N, et al. Updated international consensus diagnostic criteria for eosinophilic esophagitis: proceedings of the AGREE conference. Gastroenterology. 2018;155:1022-33.

21. Agache I, Rocha C, Beltran J, SongY, Posso M, Solà I, et al. Efficacy and safety of treatment with biologicals (benralizumab, dupilumab and omalizumab) for severe allergic asthma: A systematic review for the EAACI Guidelines - recommendations on the use of biologicals in severe asthma. Allergy. 2020 ;75(5):1043-57.

22. Seegräber M, Srour J, Walter A, Knop M, Wollenberg A. Dupilumab for treatment of atopic dermatitis. Expert Rev Clin Pharmacol. 2018;11(5):467-74.

23. Sastre J, Dávila I. Dupilumab: A New Paradigm for the Treatment of Allergic Diseases. J Investig Allergol Clin Immunol. 2018;28(3):139-50.
24. Thomson NC, Chaudhuri R. Omalizumab: clinical use for the management of asthma. Clin Med Insights Circ Respir Pulm Med. 2012;6:27-40.

25. Maurer M, Rosén K, Hsieh HJ, Saini S, Grattan C, Arnau AG, et al. Omalizumab for the Treatment of Chronic Idiopathic or Spontaneous Urticaria. N Engl J Med. 2013;368:924-35.

26. Rocha R, Vitor AB, Trindade E, Lima R, Tavares M, Lopes J, et al. Omalizumab in the treatment of eosinophilic esophagitis and food allergy. Eur J Pediatr. 2011;170(11):1471-4.

27. Arasi S, Costa S, Magazzù G, Ieni A, Crisafulli G, Caminiti L, et al. Omalizumab therapy in a 13-year-old boy with severe persistent asthma and concomitant eosinophilic esophagitis. Ital J Pediatr. 2016;42:32.

28. Loizou D, Enav B, Komlodi-Pasztor E, Hider P, Kim-Chang J, Noonan $\mathrm{L}$, et al. A pilot study of omalizumab in eosinophilic esophagitis. PLoS One. 2015;10: e0113483.

29. Clayton F, Fang JC, Gleich GJ, Lucendo AJ, Olalla JM, Vinson LA, et al. Eosinophilic esophagitis in adults is associated with IgG4 and not mediated by IgE. Gastroenterology. 2014;147(3):602-9.

30. Hom S, Pisano M. Reslizumab (Cinqair): An Interleukin-5 Antagonist for Severe Asthma of the Eosinophilic Phenotype. Pharmacology \& Therapeutics. 2017;42(9):564-8.

31. Markowitz JE, Jobe L, Miller M, Frost C, Laney Z, Eke R. Safety and Efficacy of Reslizumab for Children and Adolescents With Eosinophilic Esophagitis Treated for 9 Years. J Pediatr Gastroenterol Nutr. 2018;66(6):893-7.

32. Spergel JM, Rothenberg ME, Collins MH, Furuta GT, Markowitz JE, Fuchs G 3rd, et al. Reslizumab in children and adolescents with eosinophilic esophagitis: results of a double-blind, randomized, placebo-controlled trial. J Allergy Clin Immunol. 2012;129(2):45663,463.e1-3.

33. Assa'ad AH, Gupta SK, Collins MH, Thomson M, Heath AT, Smith DA, et al. An antibody against IL-5 reduces numbers of esophageal intraepithelial eosinophils in children with eosinophilic esophagitis. Gastroenterology. 2011;141(5):1593-604.

34. Straumann A, Conus S, Grzonka P, Kita H, Kephart G, Bussmann C, et al. Anti-interleukin-5 antibody treatment (mepolizumab) in active eosinophilic oesophagitis: a randomised, placebo-controlled, double-blind trial. Gut. 2010;59(1):21-30.

35. Conus S, Straumann A, Bettler E, Simon HU. Mepolizumab does not alter levels of eosinophils, T cells, and mast cells in the duodenal mucosa in eosinophilic esophagitis. J Allergy Clin Immunol. 2010;126(1):175-7.

36. ClinicalTrias.gov. A study of Benralizumab in patients with Eosinophilic Esophagitis (MESSINA) [Internet]. Available in: https:// clinicaltrials.gov/ct2/show/NCT04543409?term=Benralizumab\& cond=Eosinophilic+Esophagitis\&draw=2\&rank=1. Accessed on: 10/17/2020.

37. Weidinger S, Novak N. Atopic dermatitis. Lancet. 2016;387:1109-22.

38. ClinicalTrias.gov. Study to determine the efficacy and safety of Dupilumab in adult and adolescent patients with Eosinophilic Esophagitis (EoE) [Internet]. Available in: https://clinicaltrials.gov/ ct2/show/NCT03633617?type=Intr\&cond=Esophagitis\%2C+Eosi nophilic\&draw=4. Accessed on: 10/17/2020.

39. ClinicalTrias.gov. Study to investigate the efficacy and safety of Dupilumab in pediatric patients with active Eosinophilic Esophagitis (EoE) (EoE KIDS) [Internet]. Available in: https://clinicaltrials.gov/ ct2/show/NCT04394351?type=Intr\&cond=Esophagitis\%2C+Eosi nophilic\&draw=3. Accessed on: 10/17/2020.

40. Hirano I, Dellon ES, Hamilton JD, Collins MH, Peterson K, Chehade $\mathrm{M}$, et al. Efficacy of Dupilumab in a Phase 2 Randomized Trial of Adults With Active Eosinophilic Esophagitis. Gastroenterology.2020 Jan;158(1):111-122.e10. doi: 10.1053/j.gastro.2019.09.042. Epub 2019 Oct 5.

41. Judd LM, Heine RG, MenheniottTR, Buzzelli J, O'Brien-Simpson N, Pavlic D, et al. Elevated IL-33 expression is associated with pediatric eosinophilic esophagitis, and exogenous IL-33 promotes eosinophilic esophagitis development in mice. Am J Physiol Gastrointest Liver Physiol. 2016;310(1):G13-25. 
42. ClinicalTrias.gov. A study of Lirentelimab (AK002) in patients with active Eosinophilic Esophagitis (KRYPTOS) [Internet]. Available in: https://clinicaltrials.gov/ct2/show/NCT04322708?type=Intr\&cond=E sophagitis\%2C+Eosinophilic\&draw=4. Accessed on: 10/17/2020.

43. ClinicalTrias.gov. Efficacy and safety of QAX576 in patients with Eosinophilic Esophagitis [Internet]. Available in:https://clinicaltrials. gov/ct2/show/NCT01022970?type=Intr\&cond=Esophagitis\%2C+E osinophilic\&draw=4. Accessed on: 10/17/2020.

44. ClinicalTrias.gov. Dose ranging study of RPC4046 in Eosinophilic Esophagitis [Internet]. Available in:https://clinicaltrials.gov/ct2/show/ NCT02098473?type=Intr\&cond=Esophagitis\%2C+Eosinophilic\&d raw=5. Accessed on: 10/17/2020.

45. Gann PH, Deaton RJ, McMahon N, Collins MH, Dellon ES, Hirano I, et al. An anti-IL-13 antibody reverses epithelial-mesenchymal transition biomarkers in eosinophilic esophagitis: Phase 2 trial results. J Allergy Clin Immunol. 2020;146(2):367-76.
46. ClinicalTrias.gov. Off label use of Infliximab in adult patients with severe Eosinophilic Esophagitis (IEE) [Internet]. Available in: https:// clinicaltrials.gov/ct2/show/NCT00523354?type=Intr\&cond=Esopha gitis\%2C+Eosinophilic\&draw=3. Accessed on: 09/19/20210.

47. Ko E, Chehade M. Biological Therapies for Eosinophilic Esophagitis: Where Do We Stand? Clin Rev Allergy Immunol. 2018;55(2):205-16.

No conflicts of interest declared concerning the publication of this article.

Corresponding author:

Igor Garcia Sanches de Souza

E-mail: igorsouza97@outlook.com 